\title{
Miquel de Palol: una narrativa quàntica?
}

\section{Miquel de Palol: a quantum narrative?}

\author{
Júlia Ojeda Caba \\ Universitat de Barcelona \\ jojedacaba@gmail.com \\ Data de recepció: 02/08/2018 \\ Data d'aceptació: 08/03/2019
}

\section{Resum}

El contingut d'aquestes pàgines té com a objectiu una primera aproximació teòrica general alguns dels models formals que vertebren, si no tota, gran part de la producció narrativa de Miquel de Palol. Situant els preceptes lul·lians de l'Ars magna al centre de l'arquitectura paloliana -entesos com a model logìcomatemàtic occidental per excel·lència-, veurem desenvolupats els mecanismes narratius i els elements constitutius de la seva literatura, basats en paradigmes teòrics provinents del camp de la geometria i la música, centrant-nos especialment en la construcció del punt de vista i el temps. Així mateix partirem d'una de les seves novel·les més emblemàtiques, El Testament d'Alcestis, per apuntar, sobre el text, dites qüestions. Per afegir finalment un seguit de connexions metaliteràries que ens portaran a ampliar el nostre marc referencial, des del grup Oulipo a Joyce o Borgues, amb la intenció d'assentar les bases teoricoliteràries d'un escriptor tan polifacètic i complex com és Miquel de Palol i Muntanyola.

Paraules clau: Miquel de Palol; narrativa catalana contemporània; combinatòria lul·liana; hipertextualitat.

\begin{abstract}
These pages have the aim to become a first theoretical and general approach to some formal models that are crossing, if not all, much of the narrative production of Miquel de Palol. Locating the main lullius statements from the Ars Magna in the center of Palol's architecture - understanding those as the western logical-mathematical paradigm par excellence- it will be developed the narrative mechanisms and the constituting elements from his literature, that come from fields such geometry or music, with a special focalization in the construction of the Point of view and Time. Starting from one of Palol's most emblematic novels, El Testament d'Alcestis, for pointing out all these questions. Finally, trying to increase our referential bibliography, it will be set a sort of metaliterary connexions, from the Oulipo's group to Joyce or Borges, with the intention to settle down the theoretical and literary bases for such a multi-faceted and complex writer as Miquel de Palol i Muntanyola.
\end{abstract}

Keywords: Miquel de Palol; contemporary catalan narrative; lullius combinatory; hipertextuality. 
$-442$ 


\section{Taula de continguts}

1. Miquel de Palol i la seva mecànica

2. Lògica combinatòria i geometria divina o Llull com a epicentre epistemològic

3. Sincronització quàntica a El Testament d'Alcestis

4. Més enllà de l'origen: cànon universal i hipertextualitat

Bibliografia 



\section{Miquel Palol i la seva mecànica}

«Tot filòsof pot ser un bon mecànic», escrivia Ramón Llull en els seus Principis de la filosofia vora l'any 1310; per a nosaltres la transcripció complementària en termes palolians d'aquesta frase seria: Tot escriptor pot ser un bon mecànic. Al llarg d'aquest article intentarem explicar-vos el valor d'aquesta relació.

La nostra investigació se centra en l'estudi de l'obra de Miquel de Palol. Més específicament, la hipòtesi és que el conjunt d'obres titulades Exercicis sobre el punt de visaextraordinària maquinària literària formada per nou volums diferents- té com a base generatriu un únic nucli ideològic constituït per l'última novel·la del cicle, El Testament d'Alcestis. En un primer moment vam pensar d'orientar aquestes línies cap a una anàlisi textual -potser més formal i didàctica-, tot emprant una metodologia inductiva que ens permetés desglossar el seguit d'elements que formen part del que Palol anomena el «Joc de la Fragmentació». Però a mesura que ens endinsem en l'univers palolià ens n'adonem que és imprescindible, si en volem dir alguna cosa amb sentit, començar traçant les primeres coordenades per bastir una aproximació adequada als textos i a la poètica subjacent. En una entrevista de Vicenç Llorca per al suplement «Cultura» de l'Avui del'any 2005, Miquel de Palol mencionava l'Ars Magna de Ramon Llull com la seva obra d'assaig en català de referència. Al mateix temps, reconeixia l'arquitectura i la música com aquells dos mons que sempre li han interessat, especialment pel caràcter compositiu d'uns models formals centrats en una idea nuclear i amb una estructura de conjunt. És la confecció d'aquesta geometria literària particular el tema central que avui ens ocupa, que sens dubte troba en la seva base el que Leibniz, seguint a Llull, va batejar com a Ars combinatòria.

\section{Lògica combinatòria i geometria divina o Llull com a epicentre epistemològic}

L'empresa lul·liana, tal com assenyala Amador Vega (2016), universalment reconeguda, consistia a crear un llenguatge universal perfecte a través de la combinació lògica de termes. Es tractava d'un art -en el sentit de tècnica, i fins i tot d'estratègia- per trobar i justificar tots els coneixements a partir d'unes quantes nocions i principis primers, obtenint per combinació 
dels símbols que els representen, els continguts de totes les ciències. Un model dinàmic i a la vegada relacional d'un llenguatge que descriu la realitat alhora que assenyala el marc i el nou escenari de la creació humana: la multiplicació de les possibilitats i l'aparença d'un món infinit, tot reflectint una concepció relacional de la realitat, el que avui entendríem per xarxa. A banda de la totalitat de conjunt del model lul·lià, ens interessa especialment, en connexió amb Palol, la interrelació de totes les disciplines de l'època (astronomia, filosofia, teologia, lògica, medicina i dret) que Llull incloïa en el seu sistema de pensament,convertint-lo en el millor exemple de com posar en relació coses diferents. I la seva concreció física en una màquina lògica que fent girar discos de paper generava combinacions lògiques d'unitat, diferència, contradicció... creant de forma intuïtiva un mètode algorítmic amb normes deductives a partir d'axiomes, és a dir, una primera temptativa d'emprar models lògics per produir saber.

Tal com hem anat esbossant, el llenguatge de símbols abstractes que va proposar Lull exigia el coneixement mecànic de l'Art, segurament en el sentit que per Plató ningú hauria d'iniciar-se en la filosofia sense coneixement previ de geometria. Molt probablement aquest és el nexe d'unió i de propulsió d'aquests dos grans neoplatònics. Julià Guillamon(2010: 9), que ha estat molt immers en la narrativa paloliana, defineix el Joc de la Fragmentació com un sistema discursiu calidoscòpic amb derivacions en la historia, la política i la economia, i que s'estructura a partir dels quatre principis bàsics que regeixen la producció de ficció de l'autor: la geometria, la música, la memòria, i el sexe; i que donen peu a un sistema ideològic i epistemològic que té per missió la recerca desesperada de la unitat. Altrament, el mateix Palol també ha descrit el Joc de la Fragmentació com un sistema de coneixement que beu del neoplatonisme, de la maçoneria, dels sistemes canònics de la música barroca, etc. En definitiva, un exercici iconogràfic propi si bé fortament arrelat a una tradició. Abans de concretar l'articulació particular de la màquina narrativa de Palol i resseguir la combinatòria lul·liana, un cop ja hem començat a veure les diferents similituds, és interessant apuntar que Llull també va proveir la seva lògica amb un art de la memòria, per retenir les difícils combinacions, mitjançant símbols que simplifiquessin els termes i ajudessin a la mecanització. La sintetització mnemotècnica paloliana, d'aquesta mateixa idea, es veu concretada en la imatge tridimensional d'un dodecàedre de figura pentagonal, que ha anomenat el Troiacord. 


\section{Sincronització quàntica a El Testament d'Alcestis}

Així, doncs, hem escollit la novel·la El Testament d'Alcestis com a punt de partida en aquest primer intent d'estudi de la seva obra, no tant pel contingut o la temàtica, sinó perquè El Testament és la conjunció reduïda dels procediments narratius de dues de les seves obres de més renom, El Jardí dels Set Crepuscles d'una banda, i del'altra, El Troiacord. Palol ens mostra un conjunt de forces d'energies físiques, emocionals i mentals dels personatges convocats a un joc volumètric dins el temps, amb què recupera l'ambient de reunió-festa-joc que descriu Maria Rosell (2010: 34), i que ja trobàvem en el Jardi; on hi havia personatges que explicaven una història i dins d'aquesta història n'hi havia un altre que explica noves històries, tot seguint un procediment clàssic de gran tradició a Occident, des d'Homer a Borges, passant pel Decameró o el Quixot. I a això s'afegeix el mecanisme narratiu del Troiacord, una sèrie de situacions dins les quals es fa referència a situacions anteriors en termes de passat o de futur, on els personatges es troben per jugar, però no saben de què va el joc. L'objectiu de Palol es coordinar en tot moment els dos aspectes vertebradors de la seva narrativa: el punt de vista i el temps. D'aquesta manera, l'única possibilitat de copsar la multiplicitat de les diferents dimensions diegètiques és dins de la pròpia estructura geomètrica; tanmateix, ni en una lectura de conjunt és possible delimitar què ha vingut abans i què després, perquè el temps total, tal com ens explica el mateix Palol, no es mou en una línia progressiva, sinó dins d'una figura tancada: el dodecàedre troiacordial. Aquesta mateixa estructura és la que ens permet entendre la possibilitat combinatòria de les històries i els personatges, que alteren completament la lògica formal del temps i l'espai, i s'assimilen molt més a certs principis de la física quàntica, com bé podria assenyalar Rovelli (2016). Palol aconsegueix que sigui possible anar d'un punt $\mathrm{A}$ a un punt $\mathrm{C}$ sense passar per un punt $\mathrm{B}$, atès que interpreta el moviment resseguint les línies narratives dins de la figura geomètrica, i aquestes formen part d'aquesta màquina d'un temps que no té deus ex machina, ja que la màquina és la narració mateixa -i l'autor no és el demiürg que ens esperàvem. 


\section{Més enllà de l'origen: cànon universal i hipertextualitat}

Un cop introduït l'aspecte més tècnic ens interessa ampliar el nostre marc referencial, més enllà de Llull, i continuar el nostre diàleg palolià amb algunes idees desplegades en l'entorn de la literatura oulipiana. Abans però, ressituem-nos. El grup literari de l'Oulipo (Ouvroir de Littérature Potentielle), va ser fundat l'any 1960 per l'escriptor Raymond Queneau i el matemàtic François Le Lionnais. L'eix central dels seus estudis d'experimentació literària era el nexe d'unió entre l'art i la ciència, i atorgaven un paper destacat als recursos matemàtics i tecnològics aplicats a la creació literària. El concepte fonamental sobre el qual pivotava tot el seu ideari (tot i que el mot és inadequat i forçat), era la potencialitat o la capacitat d'una estructura per engendrar un artefacte literari, sempre que hi hagués un lector disposat a convertir en acte el que fins llavors només existia en potència, -i voilà!, sota aquesta premissa podríem incloure ja d'entrada el dodecàedre de Miquel de Palol. Altrament la majoria d'escriptors adscrits al grup, els noms dels quals van des d'Italo Calvino fins a Georges Perec, són especialment coneguts per l'ús de tècniques combinatòries aplicades, és a dir, per l'ús i la creació d'hipertextos literaris. Aquí ens interessa directament la noció d'hipertext, i algunes altres consideracions que en deriven, a l'hora d'analitzar la producció novel·lística de Palol. Ted Nelson (Gónzalez, 2012) entén per hipertext una escriptura no seqüencial configurada a partir de blocs de textos que es ramifiquen i es connecten entre si, i generen més d'un itinerari possible de lectura. Per tant, novament, i com en la màquina lul·liana, ens trobem davant d'un sistema determinat i possible de relacions. Fins al punt que resulta secundari formular una definició exacte d'hipertext, perquè, més aviat, tenim la urgència de posar-la en pràctica i de trobar una línia discursiva més general que dialogui amb aproximacions diverses i alternatives respecte a la nostra formulació.

En un article sobre textualitat electrònica, Maria Josep Llàcer Vidal, situa l'Ars Combinatoria de Ramon Llull com el precedent occidental de les vertaderes obres hipertextuals; conjuntament amb l'obra del món oriental del I Ching, que es tradueix com el Llibre dels canvis o Llibre de les mutacions, i que consisteix en un sistema combinatori de 64 hexagrames formats per línies contínues i discontínues que permeten al lector obtenir respostes a les seves preguntes mitjançant un principi aleatori que conforma les combinacions binàries que vénen a constituir el 
pentagrama. Aquestes dues obres tenen en comú l'aplicació d'un sistema precursor de sistemes combinatoris digitals i poden establir certs paral·lelismes amb l'estructura no-lineal, la lectura participativa i hipertextual. Així doncs, les paraules de Llàcer ens ajuden a crear un pont entre Llull i la literatura oulipiana, com a fonaments principals del marc teòric que estem intentant establir en la base de la narrativa de Miquel de Palol.

Autors de la talla de Joyce, Nabokob, el mateix Calvino ja mencionat, Cortázar o Borges són coneguts pel treball i la confecció d'històries multiformes i pluridimensionals que malden per mostrar la vida com una suma de possibilitats paral leles de manera simultània, o que seguint estructures similars s'erigeixen com a veritables amants del bricolatge i el collage literaris, termes emprats per Lévi-Strauss i Guille Deuleze. Nosaltres ens atrevim a dir que el nom de Miquel de Palol hauria de seguir aquesta llista de grans escriptors, i que la totalitat de la seva obra pot ser llegida com un gran edifici hipertextual. Però aquesta és una sentència que cal demostrar amb més arguments, i la deixarem suspesa en l'aire per reprendre-la en un futur... La cosa important aquí és observar com aquesta narrativa està composta per tot un seguit d'elements que s'agreguen al voltant del concepte d'hipertextualitat. Reprenent la imatge tridimensional del dodecàedre, podem copsar la ruptura aristotèlica de la linealitat. La discontinuïtat característica d'aquests textos fa palesa la inexistent seqüència necessària i probable d'esdeveniments, amb un principi, un nus i un desenllaç únic - tot multiplicant demanera exponencial la possibilitat de les histories i les veus narratives que hi puguem trobar. És a dir, ens trobem davant de fragments textuals que poden combinar-se de diferents maneres, tot creant un collage dinàmic i en constant construcció. Segons els principals teòrics de l'hipertext, tal i com ens explica Gonzàlez (2012), com ara Nelson o Landow, l'encarregat d'ordenar aquest trencaclosques no és altre que el lector, que ha de desprendre's d'una inèrcia teleològica, és a dir, de la concepció del text literari com un contínuum estructurat escatològicament per desembocar en un final únic i concloent. En el cas de Palol però, tot i que en cap cas volem menystenir l'autonomia pròpia del lector, la feina no rau tant en la confecció d'un o varis camins literaris, sinó més aviat en el fet d'endinsar-se en la xarxa de possibilitats que genera el mateix dodecàedre, sempre dins del model i l'ordre, en última instància finit, que l'autor-arquitecte ha dissenyat. Ara bé, aquest aspecte no resta res a la concepció descentralitzada de la seva estructura, que no presenta un punt d'origen i/o final, sinó 
que pot ser i és recorregut de diverses maneres, en funció del punt de vista o de la combinació que li sigui aplicada. El que sí desapareix és el sentit d'unicitat textual, en el moment en què el centre es converteix en quelcom volàtil i indeterminat que dificulta la seva aprehensió. L'aspecte final a tenir en compte en relació a tot el que hem anat explicant fins ara, i que d'alguna manera ens transporta a l'inici d'aquesta ponència, és el caràcter lúdic que presenten aquesta mena de textos, és a dir la confecció d'un joc literari-El Joc de la Fragmentació-, basat en la relació d'un seguit de regles pròpies que el lector ha de conèixer i tenir en compte.

En definitiva, la intenció en aquestes línies ha estat en tot moment la de proposar una primera base teòrica, més o menys sòlida, a partir de la qual pretenem llegir i entendre l'obra de l'autor. La seva formació en el camp de l'arquitectura i la seva passió per la música, prenent a Bach com a model, fan palesa la gran complexitat i alhora la gran ambició paloliana; la mateixa que constantment ens exigeix més atenció i més consciència cap a la matèria (com si fos la matèria del contingut) amb què les coses estan fetes, una directiva que no ens porta a cap altre lloc que a l'acte de narrar en si mateix, sense cap altre artefacte. Tal com diu a El Testament l'únic truc, l'únic ornament escènic, és la mateixa narració. 


\section{Bibliografia}

De Palol, M. (2008).El Testament d'Alcestis. Barcelona: Grup editorial 62/ Editorial Empúries.

De Palol, M. (2010). El punt de vista en les persones del verb. Text inèdit.

Gónzalez, F. (2012). Esperando a Gödel, literatura y matemáticas. Madrid: Nivola Libros y Ediciones.

Guillamon, J. (2010). «Miquel de Palol: Esplendor Geomètrico», La Vanguardia. Culturas, Volum 395, p. 9. Barcelona.

Llàcer, M. J. Dels textos predigitals a la Convergència del Pensament postmodern i la textualitat electrònica. Programa de Doctorado, Artes visuales e Intermedia. UPV. Disponible a: <http://www.upv.es/laboluz/doctorado/text/josepa_llacer.pdf> [Última consulta: $11 / 11 / 2018]$.

Llorca, V. (2005). «La geometria de Bach», en Avui Cultura. Barcelona, p. 10.

Rosell, M. (2010).«El retorn del mite», en Caràcters. Segona època, Volum 52. València, pp. 34.

Rovelli C. (2016). Set lliçons breus de física. Barcelona: Anagrama.

VVAA (2016). La màquina de pensar: Ramon Llull i l'Ars Combinatoria. Catàleg direcció: Amador Vega; autors del textos: Miquel Bassols, Fernando Domínguez Reboiras, Charles Lohr ... [et al.]. Barcelona: CCCB, Diputació de Barcelona. 